\title{
AS CONCEPÇÕES PASCALIANAS DE INFINITO E A INCOMPREENSIBILIDADE DE DEUS E DO MUNDO
}

\author{
Ivonil Parraz \\ Faculdade de Filosofia e Teologia \\ Belo Horizonte/MG
}

\begin{abstract}
The present article will intend to show that the pascalians conceptions of the infinite gifts in it I break up B.72: L.199 of the Penseés e of opúsculo Of l'esprit géométrique does not allow it to pass of the doubly infinite one to the current infinite. As well as, the references made for the philosopher to the current infinite in the fragmentos B.233; L.418 and B.793; L.308 of the Penseés aims at to designate the impossibility of the reason to understand the infinite. As consequence, the impossibility to know God and the world saw geometry: Model of the true knowledge.
\end{abstract}

Keywords: The infinite, geometry, God absconditus, universe, reason.

Resumo: O presente artigo intentará mostrar que as concepções pascalianas de infinito presentes no fragmento B.72: L.1991 dos Pensamentos e do opúsculo De l'esprit géométrique não lhe permitem passar do duplamente infinito ao infinito atual. Bem como, as referências feitas pelo filósofo ao infinito atual nos fragmentos B.233; L.418 e B.793; L.308 dos Pensamentos visam assinalar a impossibilidade da razão compreender 0 infinito. Como conseqüência, a impossibilidade de conhecer Deus e o mundo via geometria: Modelo do verdadeiro conhecimento. Palavras-chave: Infinito, geometria, Deus absconditus, universo, razão.

\section{Introdução}

A geometria ${ }^{2}$, concebida por Pascal, permite a ele trabalhar com o conceito de infinito apenas como operação e não como objeto. Isto quer

\footnotetext{
${ }_{1}^{1}$ Para as citações dos fragmentos dos Pensamentos de Pascal usaremos duas ordenações diferentes de seus pensamentos: Brunschivcg (B) e Lafuma (L).

${ }^{2}$ No século XVII, a geometria, assim como a aritmética e a mecânica, fazia parte do que era denominado as matemáticas.
} 
dizer que, para Pascal, como veremos a seguir, a razão pode operar com o conceito de infinito, sem fazer dele objeto de conhecimento, posto que o infinito escapa a todas as relações proporcionais que são propriamente o modo dela operar. Esta opção metodológica tem por finalidade ressaltar os paradoxos do infinito em detrimento da possibilidade de passar do duplamente infinito ao infinito atual. Sem isso, não há como empregar o conceito de infinito para conhecer o que quer que seja que ultrapasse a capacidade da razão. Com efeito, o recurso ao conceito de infinito é uma estratégia pascaliana para sublinhar a impotência da razão humana.

Se é possível à razão somente operar com o conceito de infinito sem fazer dele objeto de conhecimento, posto que o infinito escapa a todas as relações proporcionais que são propriamente o modo dela operar, ela é impotente para conhecer Deus: não existe nenhuma proporção entre Ele e a razão. A geometria concebida por Pascal se harmoniza com a sua teologia do Deus absconditus. Aquele que não se deixa capturar pela razão.

$O$ conceito de duplo infinito, introduzido no universo via matemática, interdita o conhecimento de sua natureza. À razão humana não é dada a possibilidade de efetuar a passagem do duplamente infinito característica principal da realidade das coisas - ao infinito atual. $\mathrm{O}$ conceito de infinito, aplicado ao mundo, interdita conhecer seus fundamentos. Somase a isso, a impossibilidade do conhecimento racional de Deus. Sem o conhecimento de Deus, não se pode atingir a origem do universo. Assim, pode-se afirmar que Pascal desenvolve a geometria porque a sua teologia é a do Deus obsconditus. No regime de um Deus que se esconde as bases do mundo físico escapam à compreensão racional.

\section{Conceito de Infinito}

Cantor insiste no fato de Pascal enunciar a possibilidade da passagem do duplo infinito ao infinito atual, quando, no fragmento B.72; L.199 dos Pensamentos, o filósofo assevera que: “(...) por mais que ampliemos as nossas concepções e as projetemos além dos espaços imagináveis, concebemos tão somente átomos em comparação com a realidade das coisas” (GARDIES, 1984, p. 65). O eixo principal deste fragmento intitulado "desproporção do homem” é o duplo infinito, no qual Pascal vê a característica principal do universo. Este duplo infinito, possibilidade de aumentar e diminuir infinitamente, está em consonância com o infinito potencial que Aristóteles 
caracteriza no livro III de sua Física: “(...) a possibilidade de ir sempre além” (ARISTÓTELES, 1926, p. 106). Assim, se há referência ao infinito atual aquele a que nada se acrescenta, no fragmento B.72; L.199, Pascal não enuncia a possibilidade de passar do infinito potencial ao infinito atual, tal como supõe Cantor.

A não possibilidade dessa passagem está em que nada se pode relacionar entre o duplo infinito e o infinito atual. A ausência de relação resulta que, embora haja um "sentimento" do infinito, pois “(...) o coração sente (...) que os números são infinitos”, (B.282; L.110), ou seja, mesmo se temos uma consciência imediata do infinito, a razão não pode penetrá-lo. Pela razão, com a ajuda do raciocínio pelo absurdo, conforme veremos, consegue-se apenas chegar ao infinito atual. Este é então inapreensível. Mas qual é a concepção deste infinito atual que, segundo Pascal, a razão não consegue apreender?

O infinito atual, tal como o concebe Leibniz, “(...) encontra-se somente no absoluto, que é anterior a qualquer composição, e não é formado pela adição das partes” (LEIBNIZ, 1980, p. 109). À luz da concepção leibniziana de infinito atual resulta que, se Pascal considera a natureza (realidade das coisas) como atualmente infinita, isto supõe que podemos conhecer sua totalidade, ou em termos pascalianos, sua existência e natureza. Ora, nada é menos certo do que atribuir a Pascal o conhecimento da natureza do universo, como veremos nas páginas que se seguem.

Pascal não só faz referência ao infinito no fragmento B.72; L.199 dos Pensamentos, como também e principalmente no fragmento B.233; L.418, intitulado "Infinito. Nada". Mas estas referências não implicam que o filósofo adentre o infinito atual, pois, para isto, seria necessária uma via de acesso a este infinito que permitisse conhecê-lo (existência e natureza) e atingir, com isso, a "realidade das coisas" em sua totalidade.

Esta via de acesso seria possível, se houvesse em Pascal a passagem da noção de duplo infinito, que ele atribui à característica principal do universo, àquela referência da "realidade das coisas" como atualmente infinita. Com efeito, a noção de duplo infinito, que aparece tanto no fragmento B.72; L.199 dos Pensamentos como no opúsculo De l'esprit géométrique, seria apenas um substrato do infinito que se chama atual.

No opúsculo De l'esprit géométrique, Pascal aplica a noção de duplo infinito ao universo: espaço, tempo, movimento, número são grandezas que podem ser aumentadas ou diminuídas infinitamente. Por mais que se 
aumente o infinitamente grande ou se diminua o infinitamente pequeno jamais se chega à totalidade ou ao nada. Sem poder ultrapassar estes limites: o nada e o todo, embora exista a possibilidade de ir sempre além, nossas concepções acerca do universo jamais se reúnem em uma totalidade. $\mathrm{O}$ infinito, tal como Pascal o emprega nesta obra, significa que há sempre qualquer coisa além, segundo a quantidade.

No fragmento B.72; L.199 dos Pensamentos, no qual o autor usa a noção de duplo infinito, encontramos o mesmo significado do De l'esprit géométrique. a possibilidade de ir sempre além sem nunca atingir o todo e o nada.

Esta noção de duplo infinito corresponde ao infinito potencial de Aristóteles: “(...) o infinito é aquilo além do qual pode-se sempre continuar a tomar qualquer coisa novamente." (ARISTÓTELES, 1926, p. 106). A noção de infinito potencial permite continuar a conceber sempre além sem a possibilidade de deter este processo. "O infinito não é aquilo fora do qual não há nada, mas aquilo fora do qual há sempre qualquer coisa" (Idem, p. 105). A própria definição de infinito potencial, do modo como Aristóteles o concebe, impossibilita qualquer tentativa de se estabelecer uma passagem ao infinito atual.

No opúsculo De l'esprit géométrique, a noção de duplo infinito é empregada não só no estudo das grandezas geométricas, também é empregada nas coisas da natureza: “(...) existem as propriedades comuns a todas as coisas, cujo conhecimento abre o espírito às maiores maravilhas da natureza. A principal compreende os dois infinitos que se encontram nas coisas, um de grandeza e o outro de pequenez" (PASCAL, 1963, p. 351b) ${ }^{3}$. No fragmento B.72; L.199 dos Pensamentos esta noção também é estendida às coisas da natureza: “(...) quando se estuda, compreende-se que, tendo a natureza gravada sua imagem e a de seu autor em todas as coisas, quase todas participam de seu duplo infinito.” (B.72; L.199). Pascal mantém, neste fragmento, a mesma ideia presente naquele outro texto: a propriedade comum de todas as coisas, ou a característica principal do universo, é o duplo infinito. "Eis a admirável relação que a natureza tem estabelecido entre

${ }^{3} \mathrm{~A}$ numeração das páginas acompanhada das letras a ou b corresponde a coluna em que se encontra a citação na referida página. 
as coisas, e as duas maravilhosas infinitudes, que ela propõe aos homens, não a conceber, mas a admirar." (PASCAL, 1963, p. 354b). A Natureza se oferece ao homem somente como objeto de admiração e não como objeto de conhecimento. A dimensão do belo que a própria Natureza propõe ao homem, admirar as maravilhas do duplamente infinito, indica a impossibilidade de uma concepção positiva do infinito (Natureza). O alvo da reflexão pascaliana, tanto em um texto como no outro, é a ausência de proporção, isto é, igualdade de relações entre o sujeito e a “(...) realidade das coisas (...)”. A referência explícita, segundo Gardies, ao infinito atual, no fragmento B.72; L.199, marca exatamente o limite que o conhecimento humano não pode atingir. Tudo o que se pode conceber (estabelecer relações) do universo é tão somente uma ínfima parte em relação à possibilidade da existência das coisas.

A noção de duplo infinito decorre da interpretação pascaliana do axioma de Eudoxo (GARDIES, 1984, p. 57-83). "Duas grandezas quaisquer, quando uma é multiplicada um número suficiente de vezes, poderá tornar-se maior que a outra.” (Idem, p. 13). A proposição I do livro X de Euclides se fundamenta sobre este axioma. Também encontra-se no livro $\mathrm{V}$ dos Elementos de Euclides a definição 4 a qual corresponde a uma definição de Eudoxo: “(...) as grandezas são ditas ter razão uma para outra, quando essas grandezas, sendo multiplicadas, podem ultrapassar uma à outra." (Idem, Ibidem). A interpretação pascaliana das proposições de Euclides encontra-se no opúsculo De l'esprit géométrique. "Euclides diz que (...) as grandezas são do mesmo gênero, quando uma sendo várias vezes multiplicada pode chegar a ultrapassar a outra." (PASCAL, 1963, p. 354a). O que equivale a afirmar que se duas grandezas são do mesmo gênero elas são homogêneas. Sendo homogêneas, elas não podem cessar de continuar em qualquer direção que seja. O espaço, por exemplo, não só pode ser multiplicado como também dividido infinitamente. Com efeito, o infinitamente pequeno é conseqüência da interpretação pascaliana da definição de Euclides (Eudoxo). A própria unidade, que Euclides não queria que fosse chamada de número, também pode ser aumentada ou diminuída ao infinito, pois: “(...) uma vez que a unidade pode, sendo multiplicada várias vezes, ultrapassar qualquer número que seja, ela é do mesmo gênero que os números precisamente por sua essência e por sua natureza imutável.” (PASCAL, 1963, p. 354a). De tudo aquilo que pode ser aumentado segue absolutamente que pode ser diminuído, pois sendo homogêneas as grandezas, e uma vez que se pode 
aumentá-las infinitamente, conforme o axioma de Eudoxo, este aumento infinito encerra a divisão infinita. $\mathrm{O}$ infinitamente grande e o infinitamente pequeno, embora diferentes, são relativos um ao outro, exatamente por sua homogeneidade. "O conhecimento de um conduz necessariamente ao conhecimento do outro.” (Idem, p. 354b). E, uma vez que a unidade é do mesmo gênero que os números, pode-se dividi-la infinitamente sem jamais chegar ao zero, exatamente por sua imutabilidade. Do mesmo modo, pode-se dividir o espaço sem jamais chegar a um indivisível; dividir o tempo sem chegar a um nada de tempo; um movimento sem chegar ao repouso. "Qualquer movimento, qualquer número, qualquer espaço, qualquer tempo que seja, há sempre um maior e um menor: de modo que estas grandezas se sustentam entre o nada e o infinito, estando sempre distantes desses extremos." (Idem, p. 352a). O duplo infinito, que Pascal concebe como propriedade comum de todas as coisas, é somente o infinito potencial, isto é, a possibilidade de ir sempre além em qualquer direção.

Pascal faz referências ao infinito não mais no sentido de duplo infinito quando afirma no fragmento B.233; L.418 dos Pensamentos que: “(...) a unidade acrescentada ao infinito em nada o aumenta, como não aumenta uma medida infinita um pé que a ela se acrescente.” (B.233; L.418). $\mathrm{O}$ infinito tomado neste fragmento implica que a ele nada se pode acrescentar. Também no fragmento B.793; L.308 dos Pensamentos, no qual Pascal estabelece a distinção entre as três ordens, ordem do corpo, ordem do espírito e ordem da caridade, encontra-se referência explícita ao infinito atual. Não há nenhuma relação entre as três ordens. A ordem da caridade não precisa das grandezas carnais nem das grandezas espirituais. Estas grandezas “(...) não acrescentam nem retiram nada (...)” (B.793; L.308) daquela. A distância infinita (ausência de relações) de uma ordem à outra, faz com que uma ordem não acrescente nem retire nada da outra.

$\mathrm{O}$ infinito ao qual Pascal faz referências naqueles fragmentos (B.233; L.418 e B.793; L.308) opõe-se ao infinito aristotélico, tal como aparece na Física. Sempre tomando um conceito negativo do infinito, Aristóteles chega a uma conclusão contrária àquela corrente que considera o infinito como aquele fora do qual não existe nada. $\mathrm{O}$ que resulta em perfeito e total. Para Aristóteles, ao contrário, o infinito é aquele fora do qual há sempre algo, do qual se pode tomar sempre um outro em um desenvolvimento sem fim. $\mathrm{O}$ perfeito e o todo, diz Aristóteles, é aquilo fora do qual não existe nada; enquanto que aquilo fora do qual há sempre algo, não é um todo, isto é, não 
é completo. Não é perfeito aquilo que encerra uma incompletude. O infinito é, por sua essência, privação: “(...) seu ser é privação.” (ARISTÓTELES, 1926, p. 108). O conceito negativo de infinito (incompletude) encerra, em si mesmo, o sentido de processo cujo desenvolvimento é sem término: “(...) a infinitude não é permanência, mas devir." (Idem, p. 107). Ora, uma vez que “(...) a unidade não acrescenta nada ao infinito, nem um pé a uma medida infinita” (B.233; L.418), como também as três ordens “(...) não acrescentam nem tiram nada” (B.793; L.308) uma da outra, parece ser bem do infinito atual de que trata Pascal. Diferentemente do conceito negativo do infinito aristotélico, o infinito tomado por Pascal nos fragmentos B.233; L.418 e B.793; L.308 é sem privação. Considerando o processo de adição sempre contínuo, Pascal chega ao infinito que não é susceptível de acréscimo: a unidade nada acrescenta ao infinito.

O infinito a que chega Pascal estaria em concordância com o infinito que, em sua III Meditação Metafisica, Descartes atribui a Deus?: “(...) concebo Deus atualmente infinito em tão alto grau que nada se pode acrescentar à soberana perfeição que ele possui.” (DESCARTES, 1973, p. 117). Ao infinito atual nada se pode acrescentar. Correspondendo assim ao infinito de que fala Leibniz:

(...) Deus é absolutamente perfeito, pois a perfeição é, apenas, a grandeza da realidade positiva tomada rigorosamente, excluídos os limites ou restrições nas coisas em que os há. E onde não houver quaisquer limites, quer dizer, em Deus, a perfeição é absolutamente infinita. (LEIBNIZ, 1983, p. 109).

A perfeição e a infinitude são termos que se relacionam um ao outro. A perfeição, para Leibniz, não é outra coisa que a infinitude, assim como para Descartes. Ao que é perfeito nada pode faltar. A própria noção de perfeição implica então a abolição de limite. Ora, é esta ausência de limite que assevera Pascal quando diz, no fragmento B. 233; L.418, que “(...) não conhecemos a natureza do infinito porque este não tem limite". Assim se a noção de infinito implica a ausência de limite, a natureza do infinito nos é desconhecida.

Ao contrário do infinito potencial, que é um processo inesgotável, portanto, por mais que se acrescente ou que se diminua não se chega a seu término, o infinito, tal como Pascal o toma nos fragmentos B.233; L.418 e B. 793; L.308 é caracterizado pela ausência de limite. Mas, é possível pensar em 
grandezas abolindo a noção de limite? Como poderíamos conceber uma tal grandeza?

As três ordens são definidas por Pascal como grandezas heterogêneas: as grandezas carnais não têm qualquer relação com as grandezas espirituais; as grandezas da caridade não têm nenhuma relação com as grandezas carnais e espirituais, pois não acrescentam nem retiram nada. A distinção dessas três ordens é de ser "diferentes de gênero", uma vez que não há relação entre elas (B.793; L.308). Assim, a definição das três ordens resulta da interpretação pascaliana da definição de Eudoxo. Uma grandeza, sendo multiplicada, pode ultrapassar uma outra somente se houver razão entre elas, ou seja, se elas forem do mesmo gênero (homogêneas). A própria definição de coisas do mesmo gênero (homogêneas) permite ao filósofo definir as três ordens como heterogêneas. "Um indivisível, multiplicado tantas vezes quanto se queira, não fará jamais uma extensão. Portanto ele não é do mesmo gênero da extensão, pela definição de coisas do mesmo gênero" (PASCAL, 1963, p. 354a).

Do mesmo modo é a relação entre "(...) o zero e o número, entre o repouso e o movimento, entre um instante e o tempo."; como também a relação entre "(...) o ponto e a linha, a linha e a superfície, a superfície e o sólido." (Idem, p. 138a). "Todas essas coisas são heterogêneas às suas grandezas, porque, sendo infinitamente multiplicadas, elas não fazem outra coisa que os indivisíveis em relação à extensão, pela mesma razão.” (Idem, p. 3554b). Em contrapartida, embora Euclides tenha recusado definir a unidade como número, ela é do mesmo gênero dos números, uma vez que, sendo multiplicada pode ultrapassar qualquer número (Idem, p. 354). Com efeito, as três ordens "não acrescentam nem retiram nada" uma da outra, porque não há razão entre elas, isto é, não são do mesmo gênero.

Se o uso que faz Pascal do axioma de Eudoxo (Euclides) permite a ele estabelecer relações ou encontrar as razões entre as grandezas, e isso por uma extrema clareza natural:

(...) pois de que os números podem sempre ser aumentados segue-se absolutamente que eles podem sempre ser diminuídos, e isto claramente: pois se pode multiplicar um número até a 100.000 , por exemplo, pode-se também tomar uma cem mil parte dividindo-a pelo mesmo número que a multiplica, e assim todo termo de aumento torna-se termo de divisão, mudando o inteiro em fração. De sorte que o 
aumento infinito encerra necessariamente também a divisão infinita. (PASCAL, 1963, p. 354b).

As suas reflexões sobre os dois infinitos, utilizando-se do axioma de Eudoxo, não lhe permitem ir, por um lado, conforme aponta Gardies, “(...) além do infinito potencial da tradição aristotélica” (GARDIES, 1984, p. 82). Por outro lado, o uso que o filósofo faz da definição de Eudoxo, aplicada à distinção das três ordens (as grandezas heterogêneas) permite a ele chegar ao infinito. Assim, Pascal chega ao infinito não somente por uma evidência natural, mas pela via indireta da definição. Esta via indireta encontra-se no fragmento B.233; L.418.

Neste fragmento, o filósofo chega, conforme vimos, ao infinito: aquele que não é susceptível de acréscimo. Esta concepção de infinito estaria em concordância com o infinito atual de Descartes e de Leibniz? Pascal, nesse fragmento, trabalha com os conceitos de unidade e de medida. Tanto uma quanto a outra são desproporcionais em relação ao infinito atual. Ambos os conceitos são próprios da matemática. Com efeito, se eles são desproporcionais ao infinito e, uma vez que são conceitos matemáticos, a geometria (parte das matemáticas), que trabalha com os objetos proporcionais entre si, não atinge o conhecimento verdadeiro do infinito. Seguindo esta linha de raciocínio, no mesmo fragmento B.233; L.418, um pouco mais adiante, Pascal assinala a impossibilidade de se conhecer o infinito -e por extensão Deus o qual Descartes e Leibniz acreditam atingi-lo pelo conceito de infinito atual- através da geometria.

Pascal trabalha nesta altura do fragmento citado com as grandezas do mesmo gênero, isto é, o número e a unidade. Aplicando a estas grandezas o processo sempre contínuo da adição, afirma que: “(...) sabemos que é falso que os números sejam finitos, logo é verdade que há um infinito em número. Mas não sabemos o que ele é: é falso que seja par, é falso que seja ímpar, pois acrescentando-lhe a unidade ele não muda de natureza" (B.233; L.418). Pascal chega ao infinito do número não por um raciocínio direto, isto é, pelo encadeamento de ideias claras e distintas como propõe Descartes, mas utilizando-se do raciocínio pelo absurdo: “(...) sabemos que é falso que os números sejam finitos, logo é verdade que há um infinito em número.” (B.233; L.418). Embora cada número seja finito, o conjunto dos números não é. E isto resulta da própria definição de número proposta por Euclides: “multidão de unidades" (COUTURAT, 1973, p. 348), uma vez que a unidade, 
sendo multiplicada várias vezes, pode ultrapassar qualquer número, o conjunto destes não é finito. Isto está em consonância com o que assevera Santo Agostinho acerca dos números: “(...) os números, em particular, são finitos; todos juntos são infinitos.” (AGOSTINHO, 1990, p. 83). A isto não se pode chegar por uma inferência direta, mas somente através de uma prova pelo absurdo. Pois, como podemos conceber, sem cair em contradição, que a união de finitos engendra um infinito? Eis a razão da utilização, por Pascal, do raciocínio pelo absurdo.

Do número infinito não se conhece sua natureza, pois acrescentandolhe a unidade ele não muda de natureza. Definem-se os números finitos como par e ímpar. Esta definição, específica dos números finitos, não se aplica ao número infinito. Ao acrescentar ao número infinito (n) a unidade (1) ele não muda de natureza. Paridade e imparidade que têm sentido no finito cessam de ter no infinito. Tomando-se que todo número é par ou ímpar, o número infinito será, ao mesmo tempo, par e ímpar (GARDIES,1984, p. 121). O que é uma contradição manifesta. Com efeito, não sabemos o que é o número infinito. Nossas concepções permitem conhecer (existência e natureza) o finito, por ser desta natureza, possui proporção, isto é, relação conosco: “(...) conhecemos a existência e a natureza do finito, porque somos finitos e extensos como ele.” (B.233; L.418). Ignoramos a natureza do infinito, porque não temos (no que se refere à natureza) nenhuma relação com ele: “(...) conhecemos a existência do infinito e ignoramos a sua natureza, porque tem extensão como nós, mas não limite como nós.” (B.233; L.418). A ausência de limite, que caracteriza o infinito interdita qualquer tentativa de conhecê-lo positivamente. A razão, que conhece estabelecendo relações, diante do infinito (sem limite) e o finito (limitado) não tem meios para ligar um ao outro. Do mesmo modo que há uma "distância infinita" entre as três ordens, há também entre o finito e o infinito (atual). Se há meios para conhecer a existência do infinito (conjunto dos números) é porque o número finito tem proporção com o infinito em número: a extensão. A extensão, portanto, é o meio que a razão encontra para estabelecer relações entre o finito e o infinito. E se podemos assim conhecer a existência do infinito é porque não há contradição entre o finito e o infinito. Ora, é bem esta a ideia geral em Matemática de existência: significa coerência (não contradição) (HILBERT apud RADICE, 1981, p. 110).

A descoberta da existência do infinito não oferece segurança alguma. Por isso mesmo Pascal hesita: “(...) entretanto, é um número” (o número infinito), "e todo número é par ou ímpar (é verdade que isso se refere a todo 
número finito)" (B.233; L.418). Por mais contraditório que possa parecer, o número infinito não é nem par nem ímpar e ao mesmo tempo é par e ímpar; admiti-lo é uma necessidade que decorre da própria possibilidade de aplicar a analogia entre a unidade e o infinito (em número), posto que há razão entre ambos: a extensão. Através da analogia (proporção, igualdade de relações) a finitude nos faz admitir a existência do infinito, mas sem poder compreendêlo. Assim, uma vez que podemos conhecer a existência do infinito mesmo não compreendendo sua natureza, “(...) pode-se, pois, conhecer que há um Deus sem se saber o que é” (B.233; L.418). Mas é possível conhecer, pelas luzes naturais, sequer a existência de Deus?

\section{Deus incompreensível}

Pelo fato de nosso entendimento ser finito, não podemos conceber positivamente o conjunto infinito dos números. Todavia, uma vez que é falso que este conjunto seja finito, nosso entendimento, ainda que finito, deve deduzir a infinitude desse conjunto. Assim, pode-se supor, com a ajuda do raciocínio pelo absurdo, que Pascal introduz, conforme aponta Gardies (GARDIES, 1984, p. 118), o tema fundamental: podemos conhecer a existência de qualquer coisa da qual nós ignoramos a natureza. Por conseqüência, podemos conhecer a existência de Deus sem saber o que é ele.

É ilusório imaginar que pela razão (geométrica) pode-se chegar ao conhecimento, pelo menos, da existência de Deus. "Se há um Deus, ele é infinitamente incompreensível” (B.233; L.418). A possibilidade de se chegar à existência do infinito resulta da homogeneidade entre a unidade e a infinitude, pois sendo dada a unidade (grandeza que pode ser aumentada ou ser diminuída infinitamente) há um número infinito de objetos parecidos, de modo que a unidade e a infinitude parecem, às vezes, ser equivalentes. De tal modo que, considerando a série dos números, não há razão para deter-se num tal número da série, mas, ao contrário, há sempre razão para avançar infinitamente ${ }^{4}$. A semelhança (razão) entre a unidade e o infinito (dos

4 Cf. LEIBNIZ. Novos ensaios sobre o entendimento humano. LII, c.XVII, p. 109-110. "Filoleto: acreditamos que, sendo sempre o mesmo o poder que o espírito tem de aplicar sem fim a sua idéia do espaço por novas adições, seria dali que deriva a idéia de um espaço infinito. Teófilo: convém acrescentar que é porque vemos que a mesma razão subsiste sempre [...] de maneira que a consideração do infinito vem da consideração da semelhança ou da mesma razão, e a sua origem é a mesma que a origem das verdades universais e necessárias". 
números) permite chegar à sua existência. Ora, entre Deus (infinito) e o homem (finito) não há semelhança (razão) alguma: pois, (Deus), “(...) não tendo partes nem limites, não tem nenhuma relação conosco” (B.233; L.418). Não havendo razão entre o homem e Deus, sua existência ou sua não existência não podem ser determinadas pela razão: “(...) há um caos infinito que nos separa" (B.233; L.418). O infinito (Deus) "sem partes nem limites” não equivale ao infinito em número. A possibilidade de estabelecer analogia entre a unidade e o infinito (em número) decorre, conforme vimos, da própria característica (homogeneidade) do espaço euclidiano: a existência de figuras semelhantes. Entre o homem (finito) e Deus (infinito) não é possível estabelecer analogia alguma, e por via de conseqüência, a existência ou não de Deus não se impõe à razão. Não tendo nenhuma relação conosco Deus está fora da captura da razão. $O$ Deus pascaliano não é identificado às verdades geométricas. O conhecimento destas não redunda no conhecimento de Deus. Com efeito, nenhum discurso é possível sobre ele. Diante da divindade só cabe à razão o silêncio.

Assim, se Pascal faz referência explícita ao infinito atual no fragmento B.72; L.199 e B.233; L.418, conforme aponta Cantor o conhecimento deste não implica no conhecimento de Deus, conforme sustentam Descartes e Leibniz.

Se bem que Descartes, assim como Pascal, afirma a incompreensibilidade do infinito - “(...) ainda que eu não compreenda o infinito” (DESCARTES, 1973, p. 116) - a concepção do infinito é muito clara e distinta; “(...) pois é da natureza do infinito que minha natureza, que é finita e limitada, não possa compreendê-lo.” (Idem, p. 116). Mesmo não compreendendo, Descartes estabelece a correspondência entre a ideia de perfeição (infinitude), concebida pela luz natural, e Deus. Assim, o filósofo chega, pela razão, à infinitude (Deus). É impossível a Pascal uma tal correspondência, pois, enquanto para Descartes a luz natural é ligada à razão, para Pascal é ligada ao coração. Pascal chama esta luz natural de sentimento natural que, por sua vez, pode ser traduzida como consciência imediata. É por esta consciência imediata (sentimento) que se chega a infinitude (Deus):

(...) sinto que posso não ter existido; pois o eu consiste no meu pensamento: portanto, eu, que penso, não teria existido se minha mãe tivesse morrido antes de eu ter sido animado: portanto, não sou um ser necessário. Não sou também eterno, 
nem infinito; mas vejo bem que há na natureza, um ser necessário, eterno e infinito. (B.469; L.135).

A referência à infinitude divina que faz Pascal decorre da consciência imediata, isto é, do sentimento do coração. Atribuir a consciência imediata ao coração, e não à razão como faz Descartes, permite a Pascal referir-se à infinitude divina mesmo que esta, ao contrário do infinito em número que tem relação com o número finito, não tenha nenhuma relação (razão) com a finitude humana. Ao contrário de Descartes, que vê a possibilidade de um encadeamento lógico a partir do eu penso até a ideia de Deus, Pascal não reconhece tal possibilidade: da finitude do eu penso, contingente no interior do tempo, não pode passar à ideia de infinitude (Deus). Da não necessidade do eu, "que pensa", não há possibilidade de deduzir a necessidade de Deus. Partindo do sentimento da existência de Deus, ou seja, desse princípio primeiro não há meios de determinar objetivamente a sua existência .

Ao contrário de Pascal e Descartes, o infinito para Leibniz é compreensível $^{5}$. A infinitude não é atribuída somente a Deus; o filósofo a atribui também às substâncias (mônadas). Todas as substâncias (mônadas) percebem o infinito e são distinguidas por ele: cada substância representa o infinito através das ideias claras e distintas que dele têm. Perceber "(...) é representar a multiplicidade na unidade ou na substância simples” (LEIBNIZ, 1983, p. 106). Disso resulta a relação ao infinito: “(...) cada mônada, cuja natureza é representativa nada consegue limitar à representação de uma só parte das coisas (...). Todas tendem confusamente para o infinito, para o todo (...)” (Idem, p. 110). Ao invés de opor, como Pascal e Descartes,

\footnotetext{
${ }^{5}$ Cf. BELAVAL, Y. Leibniz critique de Descartes. Paris: Gallimard, 1960. p. 355-368. O autor procura mostrar que Descartes sustenta a anterioridade do conhecimento positivo do infinito sobre 0 conhecimento do finito, mas ele faz desse infinito um objeto do pensamento, escapando, por definição, à capacidade de nosso entendimento compreendê-lo, ou seja, o infinito nos é incompreensível. Este entendimento passivo não exprime um mundo inteligível que se possa abraçar. Assim, Descartes pode compreender 0 infinito somente como um objeto indefinido capaz de receber as determinações, mas incapaz de ser a fonte. Leibniz, ao contrário, concebe positivamente 0 infinito não só como atividade do espírito, mas também como objeto do pensamento. Com efeito, embora limitado, nosso entendimento abraça o infinito. Encontramos em nós um infinito poder de recorrência que permite ir além, não como sustenta Descartes, dos limites do nosso entendimento, mas dos limites do perceptível. "Pela continuidade, a noção positiva do infinito torna-se princípio de determinação. Com a continuidade, eis a passagem ao limite e as quantidades auxiliares evanescentes". O método infinitesimal substitui o método dos limites que evitava a passagem ao limite. O infinito em Leibniz torna-se Ciência.
} 
seres finitos (criatura) ao ser infinito (Deus), Leibniz considera as substâncias como seres, a seu modo, infinitos:

(...) toda substância é como um mundo completo e como um espelho de Deus, ou melhor, de todo o universo, expresso por cada uma à sua maneira, pouco mais ou menos como uma mêsma cidade é representada diversamente conforme as diferentes situações daquele que a olha. (LEIBNIZ, 1983, p. 125).

As substâncias, fechadas sobre si mesmas "sem portas nem janelas", são como um mundo, nada lhes é exterior. A interioridade das substâncias é abertura para o infinito.

Leibniz chega a comparar as substâncias a Deus: uma “(...) divindade diminutiva” (BURBAGE; COUCHAN, 1993, p. 117-119). Com a diferença que, enquanto as substâncias sentem tudo confusamente Deus sabe tudo distintamente, ou seja, o infinito é percebido pelas substâncias nos limites de um certo ponto de vista, enquanto Deus é liberado de todo ponto de vista (Idem, p. 117-119) $)^{6}$.

Se para Leibniz é uma heresia Espinosa fazer do centro de sua filosofia a identificação de Deus à Natureza, não menos heresia é, aos olhos de Pascal, tomar as substâncias como se elas fossem um Deus em miniatura. É impossível a comparação entre as substâncias e Deus pretendida por Leibniz, uma vez que, para Pascal, só podemos conhecer aquilo com que temos relações (proporção). Não havendo nenhuma relação entre o homem e Deus, a semelhança é um delírio.

Se a razão, esta faculdade discursiva, só pode tratar das coisas com as quais tem relação, tratar do infinito (atual) é um não sentido. Como nós homens somos a mistura de alma e corpo, conforme Pascal expõe no fragmento B.72; L.199, não concebemos as naturezas simples. O infinito é sempre relacionado com o finito. Assim, longe de ser idêntico ao infinito (atual), o infinito em número a que chega Pascal é a infinita possibilidade coerente de sempre acrescentar a unidade ao número sem jamais encontrar uma razão que detenha este processo. Porque não tem um último termo, o conjunto dos números é infinito. Diferentemente do infinito potencial, cuja

${ }^{6} \mathrm{O}$ estudo de Burbage e Couchan sobre a busca leibniziana de construir uma ciência do infinito nos inspiraram nessas nossas considerações sobre o filósofo. 
característica é o limite, ou seja, tende para um limite sem jamais atingi-lo, o infinito, ao qual Pascal se refere, não tem limite. Longe de ser uma carência, tal como julga Aristóteles, a infinita possibilidade de lhe acrescentar algo é marca de sua infinitude, uma vez que acrescentando-lhe algo ele não muda de natureza. E, por não mudar de natureza com o acréscimo da unidade, o infinito não reclama acréscimo algum.

Mesmo não tendo limite, Pascal não atribui ao infinito a simplicidade. Aquele não é decorrência desta. A razão pela qual o filósofo não atribui ao infinito a simplicidade deve-se, por um lado, à composição do nosso ser; e por outro, a que a ideia do infinito não é uma evidência que se encontra em nosso espírito. A ideia do infinito surge na relação que se opera nas matemáticas. Não é, portanto, uma ideia anterior da qual se usa para conhecer as coisas, mas surge exatamente no conhecimento, ou nas relações que se procura estabelecer entre as coisas. O filósofo distancia-se assim de Descartes e Leibniz.

Tanto Descartes como Leibniz partilham da concepção de que a ideia do infinito (atual) está presente em nós. Para o primeiro, a ideia de perfeição (infinitude) está presente em nós como sementes de verdade. A ideia do infinito (perfeição), que corresponde a Deus, esta ideia “(...) como a ideia de mim mesmo, ela nasceu e foi produzida comigo desde o momento em que fui criado(...). É como a marca do operário impressa em sua obra.” (DESCARTES, 1973, p. 120). Leibniz, por sua vez, concebe a ideia do infinito, “(...) o infinito propriamente dito (...)” (LEIBNIZ, 1980, p. 110), como presente em nosso interior assim como a ideia do ser. Esta ideia, segundo o autor, “(...) é do mesmo gênero que as verdades universais e necessárias” (Idem, p. 110). Sua demonstração só pode provir da própria razão (Idem, p. 9). Por encontrar-se em nosso interior (razão), a ideia do infinito atual (Deus) permitirá a ambos os filósofos chegar a este infinito e, conseqüentemente, desenvolver, pela via racional, suas implicações. Em Descartes, o encontro desta ideia garante a verdade do "eu penso". Em Leibniz, as substâncias percebem, embora de maneira confusa, o infinito. Além disso, esta ideia presente em nosso interior, possibilita aos dois filósofos chegarem ao conhecimento da existência de Deus. Com efeito, de uma ideia (a ideia do infinito presente no 
interior do eu que pensa) os dois autores chegam à sua conclusão: Deus existe.

Em Pascal, o que está presente em nosso interior são as "noções primitivas" ou "nomes primeiros" que são conhecidos por todos. Estas "noções primitivas" não se encontram na razão, mas no coração:

(...) o conhecimento (...) da existência de espaço, tempo, movimento, número, é mais firme que nenhum dos que nos proporcionam os nossos raciocínios. E sobre esses conhecimentos do coração (...) é que a razão deve apoiar-se e basear todo o seu discurso. (B.282; L.110).

Estas "noções primitivas", cuja existência é conhecida pelo coração, não podem ser demonstradas. $O$ que delas todos conhecem não são suas essências, mas a “(...) relação entre o nome e a coisa”. "Não é a natureza dessas coisas que eu digo que é conhecida por todos; é simplesmente a relação entre o nome e a coisa.” (PASCAL, 1963, p. 350b). Por causa disso é que as "noções primitivas" não necessitam de definições, pois estas “(...) são feitas somente para designar as coisas que se nomeiam, e não para mostrar a natureza." (Idem, p. 350b) ${ }^{7}$.

O que Pascal chama, no opúsculo De l'esprit géométrique, de luz natural, nos Pensamentos ele vai empregar um outro termo para designá-la: coração. Isto se justifica principalmente no fragmento B.282; L.110: “(...) o coração sente que há três dimensões no espaço e que os números são

\footnotetext{
7 ARNAULD, A.; NICOLE, P. La logique ou l'art de penser. Paris: Flammarion, 1970. A inteligibilidade das "noções primitivas" marca o limite do conhecimento humano. Este tema também é apresentado por Arnauld e Nicole no I capítulo da IV parte. Louis Marin, na introdução dessa obra sustenta que: "[...] para traçar os limites da certeza e da incerteza internas à noção de ciência, para marcar as fronteiras exatas e assim assegurar o espírito em sua reflexão, Arnauld e Nicole são conduzidos, para além de Descartes e Santo Agostinho, a colocar a questão do infinito". A referência a Pascal é essencial. Em Pascal, os autores encontram o tema fundamental do limite que é aquele do infinito: "[...] é ridículo querer encerrar nos limites estreitos de nosso espírito [...] tudo aquilo que tem o infinito; pois nosso espírito sendo finito, ele se perde e se ofusca na infinidade e permanece oprimido sob a multidão dos pensamentos contrários que ela oferece" (p. 363). Trata-se, nesse capítulo, do problema dos limites do conhecimento, do "[...] discernimento que os filósofos devem ter, das coisas em que o espírito pode chegar e daquelas que ele não é capaz de atingir". As especulações acerca do infinito nos ensinam "[...] a conhecer os limites do nosso espírito, a entender que há coisas que existem ainda que não sejamos capazes de compreendê-las" (p. 366). As "noções primitivas" são exemplos dessas coisas das quais temos certeza de sua existência, mas que não somos capazes de prová-las pelo raciocínio.
} 
infinitos”. Como também no fragmento B.469; L.135 no qual Pascal se refere à consciência imediata do infinito: a “(...) existência de um ser necessário, eterno e infinito". Assim, o conhecimento (consciência imediata) do infinito é apreendido pelo coração. Todavia, dessa consciência imediata, primeira, não há possibilidade de chegar à sua outra conseqüência. Pelo fato de que temos uma consciência imediata do infinito, não podemos provar a existência de um ser infinito. Isto se verifica no caso dos números. Se sentimos que os números são infinitos; e se podemos chegar à infinitude dos números, não podemos conhecer (existência e natureza) do número infinito positivamente. Ou melhor, se Pascal chega ao número infinito (B.233; L.418) ele aponta a não possibilidade de intelecção da ideia de número infinito: "não sabemos o que ele é". Com respeito a Deus, não é possível chegar nem mesmo à sua existência, pois não há, tal com se depreende do fragmento B.469; L.135, consistência no eu: a contingência do eu no interior do tempo "não teria existido se minha mãe tivesse morrido antes de eu ter sido animado" - não se liga à necessidade divina vinculada à eternidade. Assim, se é possível chegar à existência do número infinito, dado que há homogeneidade entre unidade e número, entre o eu e Deus não há nenhuma homogeneidade. Tempo e eternidade são heterogêneos. A luz natural (sentimento natural) não oferece meios de estabelecer nenhum vínculo entre a ideia e a existência das coisas de que se tem à ideia.

Enquanto em Descartes e em Leibniz há um saber do infinito, pois há no homem a ideia do infinito (Deus), as noções primitivas o coração apenas as sente. E uma vez que elas não necessitam de definições, não são conhecidas pela razão. São estas "noções primitivas" que o coração fornece à razão e que são as bases para que esta, estabelecendo relações, empreenda seu discurso. $\mathrm{O}$ trabalho da razão é exatamente este: estabelecer relações entre as noções primitivas e outros objetos. Ora, com a ideia do infinito atual, a razão não pode estabelecer relação alguma, pois não há nada que se relacione a ele. Por isso mesmo que Deus, infinito atual, não tem partes nem limites, é incompreensível. Embora Deus seja sentido (consciência imediata) pelo coração, a razão nada tem a fazer com este sentimento. Deus é objeto de crença, não de especulação racional. "Mesmo que as proporções dos números sejam verdades imateriais, eternas e dependentes de uma primeira verdade em que subsistem.” (B.556; L.449), e por isso pode-se chegar à existência do número infinito, no conhecimento de Deus não há nenhuma primeira verdade que se possa, estabelecendo um encadeamento racional, determinar 
sua existência. Com efeito, o conhecimento que se pode ter das matemáticas, não se aplica ao conhecimento de Deus. Julgar que com o conhecimento matemático pode-se atingir o conhecimento divino é mera presunção dos filósofos. O Deus que julgam atingir é “(...) um Deus simplesmente autor de verdades matemáticas e da ordem dos elementos.” (B.556; L.449). É, portanto, uma ilusão, não o verdadeiro Deus.

A ausência de limite do infinito pascaliano não decorre da simplicidade absoluta como em Leibniz; decorre da ausência de uma razão que detenha o processo de sempre acrescentar a unidade ao infinito como é o caso dos números. O infinito é pensado não a partir da ideia de infinito (atual), o que implica tal ideia presente em nosso interior, mas da própria "ordem da geometria":

(...) que é a verdade inferior naquilo que ela é menos convincente, mas não naquilo que ela é menos certa (...), ela supõe somente as coisas claras e constantes pela luz natural, e porque ela é perfeitamente verdadeira, a natureza sustenta em lugar do discurso. (PASCAL, 1963, p. 350a).

A ordem da geometria repousa então sobre a luz natural, “(...) as coisas claras e entendidas por todos os homens (...)”, a "(...) inteligência nítida sem palavras que a natureza deu aos homens (...)"; "a extrema evidência” (PASCAL, 1963, p. 350b-351b). Esta ordem da geometria, que não conduz ao conhecimento da natureza das coisas, mas apenas ao conhecimento da relação que há entre elas, permite encontrar o infinito. Com efeito, se o infinito é pensado pela luz natural, tal como concebe Descartes, em Pascal, o infinito é pensado como operação e não como objeto (CHEVALLEY, 1995, p. 31).

Pela possibilidade de acrescentar a unidade aos números, uma vez que ambos são homogêneos, Pascal chega, conforme vimos, ao infinito em número. O que vai arrancar de Cantor a felicitação ao filósofo moderno de “(...) pronunciar-se em favor dos números infinitos atuais.” (GARDIES, 1984, p. 117). Porém, Pascal não adentra o universo dos números infinitos atuais. Embora haja sempre a possibilidade de acrescentar a unidade ao número infinito, o que tem por conseqüência, que o número infinito não é o maior de todos os números - e isso é correto quanto aos números infinitos atuaishá também a questão de saber se os números infinitos atuais são iguais. Pascal hesita: o número infinito não muda de natureza acrescentando-lhe a 
unidade (B.233; L.418). Ora, é um princípio errôneo supor que “(...) todos os números infinitos são iguais” (COUTURAT, 1973, p. 424). A indecisão pascaliana é nítida na última frase: a definição par, ímpar, não tem sentido para o número infinito. Este número que não se pode definir foge à ordem da geometria, que consiste em tudo definir (com exceção das noções primitivas) e tudo provar. Um passo faltou a Pascal, o de considerar o número infinito como uma totalidade, que nada mais é do que "a unidade de uma pluralidade", a totalidade da "série natural dos números" (Idem, p. 424) que, por sua vez, é uma pluralidade ${ }^{8}$. A ordem da geometria não permite a Pascal compreender os números infinitos atuais, mas apenas fazer referência explícita ao infinito atual. Entretanto ela permite a ele trazer às claras os paradoxos do infinito, que no caso do fragmento B.233; L.418 trata-se do número infinito. Permite também explicitar os limites de nossa capacidade de conhecimento: concebemos a existência do infinito, mas não sua natureza; e, como conseqüência de nossa incapacidade, não concebemos naturalmente nem a existência, nem a natureza de Deus.

A conclusão a que chega Pascal: "Deus é absolutamente incompreensível” (B.233; L.418), decorre assim de sua própria concepção de ordem da geometria, ou seja, do próprio método geométrico. Este método, que permite conhecer a relação entre as coisas, mas não sua natureza, não nos leva ao conhecimento de Deus, uma vez que não temos nenhuma relação com ele. Com efeito, se Deus é absolutamente incompreensível, isto não está posto previamente como objetivo do raciocínio pascaliano desenvolvido no fragmento B.233; L.418. Este raciocínio não visa, como julga Gardies (GARDIES, 1984P. 133) a nos conduzir àquela conclusão.

É pela ordem da geometria que o filósofo mostra a impossibilidade de conhecer Deus pelas matemáticas. É exatamente isto que encontramos no fragmento em questão. Assim, a ordem da geometria, concebida por Pascal, está em consonância com sua teologia: a do Deus absconditus. um Deus cuja existência só pode ser atingida "pela fé" e sua natureza "pela glória", isto é, um Deus a que se chega, não pelas luzes naturais, mas somente pela luz sobrenatural.

\footnotetext{
${ }^{8}$ Esta unidade (totalidade de uma pluralidade) é, na verdade, o número cardinal. 0 número cardinal da série natural "não faz parte da série". A série natural contém todos os números finitos, seu número cardinal não é nenhum número finito, logo, ele só pode ser infinito. Com efeito, "o número infinito não é um termo da série natural, mas antes um número de todos os seus termos" (COUTURAT, 1973, p. 424).
} 
Do mesmo modo, é pela ordem da geometria que o filósofo chega ao infinito somente como operação e não como objeto, pois se pode sempre adicionar ao infinito a unidade sem que ele mude de natureza. A própria utilização do raciocínio pelo absurdo mostra que ao infinito não se pode chegar por uma concepção positiva, mas apenas manipulá-lo pelas matemáticas.

A manipulação do infinito pelas matemáticas, mais especificamente, a utilização do conceito de "ponto no infinito" como operação, encontramos na Génération des Sections Coniques. Na geometria projetiva, todas as curvas: elipse (ou antábole), parábola e hipérbole podem ser consideradas como as secções planas de um cone cuja base é circular (COUTURAT, 1973, p. 272), ou em outros termos, são chamadas "secções cônicas", ou simplesmente "cônicas" as figuras obtidas por secção de um cone por um plano. No início da Génération des Sections Coniques, Pascal procura mostrar que essas figuras são engendradas pela rotação de um plano secante do cone. Obtendo, com isto, “(...) seis espécie de secções cônicas(...)" (PASCAL, 1963, p. 40a): ponto, reta e ângulo são secções cônicas obtidas, quando “(...) o plano secante passar pelo cume do cone (...)" (Idem, p. 40a); e elipse, parábola e hipérbole são secções obtidas, quando "(...) o plano secante não passar pelo cume do cone(...)” (Idem, p. 39b). Com efeito, estas figuras são obtidas como perspectivas de um círculo. É exatamente isto o que assevera Pascal no corolário da definição VI:

(...) se o olho estiver no cume do cone, e se o que se apresenta for a circunferência do círculo que está na base do cone, e se o quadro for o plano encontrando-se de uma parte e da outra à superfície do cone, então a secção cônica que é engendrada por este plano na superfície cônica, que ela seja um ponto, uma reta, um ângulo, uma elipse (ou antábole), uma parábola ou uma hipérbole, será a imagem da circunferência do círculo. (PASCAL, 1963, p. 40a).

Sob este lugar determinado (o olhar situado no cume do cone) é então possível estabelecer a relação entre as figuras.

$O$ interesse pascaliano assenta-se em uma geometria da situação das figuras, isto é, das relações entre as figuras compreendidas sob um lugar determinado. A tomada simultânea de várias figuras na mesma situação (lugar do olho) é possível, pois Pascal considera as propriedades comuns das 
diferentes cônicas como propriedades do círculo conservadas por projeção: “(...) são as imagens da circunferência do círculo.” (PASCAL, 1963, p. 40a).

A imagem, posto que é a projeção sobre o plano secante de cada ponto da circunferência, a parábola e a hipérbole são imagens do círculo somente se compreendermos que um ou dois pontos são lançados ao infinito:

(...) se o plano do quadro é paralelo a duas das geratrizes, e engendra por conseqüência uma hipérbole, é manifesto que todos os pontos da circunferência projetam suas imagens sobre o plano de visão, isto é, sobre o quadro, à distância finita, exceto dois pontos em que as imagens, por causa do paralelismo, não se encontram em nenhuma parte, se este não estiver à distância infinita (...). (PASCAL, 1963, p. 40b).

O conceito de ponto no infinito é concebido somente como operação. É o instrumento que permite tomar a diversidade das figuras na unidade da imagem. Assim, o conceito de ponto no infinito tem como função unificar todas as secções cônicas como imagem do círculo de base, ou seja, como projeção do ć́rculo sobre o plano secante. Seu único sentido é de estabelecer uma equivalência entre objetos aparentemente distintos. Sua função é, portanto, operacional. Por conseqüência, a Geometria aparece em Pascal como abertura para o infinito: um infinito que ela não compreende, uma vez que o ponto no infinito, longe de ser concebido claro e distintamente, é utilizado apenas como operação (BRÁS; CLÉRO, 1994, p. 96-126).

\section{Universo à Deriva}

A manipulação do conceito de "ponto no infinito" encontra-se no célebre pensamento pascaliano do universo: “(...) esta é uma esfera infinita cujo centro se encontra em toda parte e cuja circunferência não se acha em nenhuma (...)" (B.72; L.199). Tomado como uma esfera infinita, o centro do universo "encontra-se em toda parte", pois sendo infinita a esfera, seu centro é posto arbitrariamente no finito do plano. Sua circunferência "não se encontra em parte alguma", uma vez que é infinita a esfera. Centro e circunferência se assemelham, pois em uma esfera infinita o centro é análogo 
a um ponto inextenso (zero de extensão) e a circunferência análoga a um "ponto imenso". Cada um constitui uma unidade: centro (sem extensão), circunferência (totalidade) (COUTURAT, 1973, p. 299) ${ }^{9}$.

Da geometria projetiva pode-se concluir que os limites do pensamento geométrico são o ponto indivisível (zero de extensão) e o infinito. $\mathrm{O}$ mundo das formas imagináveis evolui entre esses limites. Entre o ponto indivisível e o infinito, isto é, entre os limites, todas as figuras se confundem e se dissipam. Com efeito, no duplo infinito perde-se toda a forma geométrica. Ela só existe no finito. $\mathrm{O}$ infinito não pode ser representado. A imaginação não pode abarcá-lo.

Enquanto no fragmento B.233; L.418 Pascal mostra a impossibilidade de a razão compreender a natureza do infinito, no fragmento B.72; L.199, mais especificamente, no pensamento acerca do universo, é a imaginação que não pode abrangê-lo. O infinito, portanto, é sem representação. Entretanto, é por sua não representatividade que Pascal o introduz na natureza, ou seja, por ser operação, pois o infinito surge, na geometria projetiva, nas relações projetivas das figuras, e não como objeto que o filósofo o introduz na Natureza, pela via matemática.

Esta via, que permite atribuir ao universo a infinitude, não permite encontrar seus fundamentos. Centro em toda parte equivale a ausência de centro, pois qualquer ponto que se tome equivale a qualquer outro. Este ponto (centro) qualquer, tomado à vontade, depende do ponto de vista. $\mathrm{O}$ ponto de vista em Pascal, diferente do de Leibniz, que nada mais é do que a expressão de cada substância, longe de ser um meio de confirmar a verdade de uma coisa ou proposição, é o meio de fazer surgir uma relação diferente (CHEVALLEY, 1995, p. 74). "As diferentes proposições (...) sendo olhadas de um outro lado, dão outras aberturas (...)” (PASCAL, 1963, p. 64b).

\footnotetext{
${ }^{9} \mathrm{O}$ autor toma o pensamento de Pascal como um plano de raio infinito.O centro do plano está em toda parte como um "ponto inextenso" ou um "zero de extensão". O centro é assim considerado "como um ponto qualquer posto à vontade no finito da superfície". Tomado o plano como infinito (esfera infinita), sua circunferência não se encontra em parte alguma". E uma vez que o plano é concebido como infinito, ele não é mais uma circunferência, dado que uma circunferência de raio infinito, no espaço euclidiano, se confunde com uma reta. Assim, o plano infinito "é uma reta ou um ponto". Ele é semelhante a um "ponto imenso". Contudo, o ponto (centro) e o plano infinito (ponto imenso) se assemelham de uma certa maneira. O ponto (centro) e o "ponto imenso" (plano infinito) constituem uma unidade, uma por sua não extensão, a outra por sua totalidade.
} 
Pois se não soubermos revirar as proposições em todos os sentidos, e se nos servirmos somente do primeiro viés que considerarmos nunca iremos muito longe: são essas diferentes rotas que abrem conseqüências novas, e que, pelas enunciações adequadas ao assunto, ligam as proposições que pareciam não ter nenhuma relação nos termos em que elas eram concebidas de início. (PASCAL, 1963, p. 65b).

São as mudanças dos pontos de vista que fazem surgir diferentes relações. São desses diferentes pontos de vista que trata Pascal no fragmento B.72; L.199, quando, em um primeiro momento, parece que o autor assume posições antagônicas: copernicano e anti-copernicano. Pode-se inferir que Pascal é um anticopernicano, uma vez que afirma a órbita ampla que o sol descreve e "(...) os astros que se espalham pelo firmamento (...)”, em torno de uma Terra representada como um ponto imóvel. Esse geocentrismo é logo desmentido quando, mais adiante, Pascal qualifica a Terra como “(...) um canto afastado da natureza (...) um ponto insignificante na órbita ampla desse astro (...)” (o sol). Estas duas proposições antagônicas são esclarecidas através de um outro texto. $\mathrm{Na}$ Lettre ao Pe. Noël, 29 de outubro 1647, Pascal sustenta que:

(...) quando se discute humanamente sobre o movimento, a estabilidade da terra, todos os fenômenos dos movimentos e retrogradações dos planetas seguem-se das hipóteses de Ptolomeu, de Ticho, de Copérnico e de muitas outras que se pode fazer, de todas as quais uma só pode ser verdadeira. Mas quem ousará fazer um tão grande discernimento, e quem poderá, sem perigo de errar, sustentar uma em prejuízo das outras, sem se tornar ridículo. (PASCAL, 1963, p. 202b, p. 203a).

A diversidade de hipóteses, surgidas de diferentes pontos de vista, impede de discerni-las. Não há um ponto de vista único, ou um ponto fixo que se possa agarrar para afirmar qual é a verdadeira, e isto devido à sua própria diversidade.

Ora, se é a mudança de ponto de vista que faz surgir novas relações e isto, decorrente da própria Matemática: modelo para o verdadeiro conhecimento do universo, ela (a Matemática) nada permite concluir acerca do universo. Sua finitude ou infinitude dependerá do ponto de vista que se toma. Considerando sua circunferência atirada ao infinito, esta não se acha em parte alguma. O universo é, portanto, 
infinito. Todavia, desse infinito só conhecemos sua existência, dada a existência de figuras semelhantes (COUNOT apud COUTURAT, 1973, p. 565-566), (as propriedades comuns das diferentes cônicas que são, por sua vez, propriedades do círculo conservadas por projeção), e não sua origem. "É igualmente incompreensível (...) que o mundo tenha sido criado e que não o tenha (...)" (B.230; L.809). O universo pascaliano não tem sustentação. A Geometria, que se abre ao infinito, desemboca na ausência da possibilidade de uma cosmologia racional. Os horizontes do universo são sempre provisórios.

A visão matemática do universo não o esgota: “(...) nossa imaginação mais rapidamente se cansará de conceber que a natureza de revelar" (B.72; L.199). O mesmo tema da revelação da natureza encontrase também no Préface sur le traité du vide. “(...) os segredos da natureza estão escondidos; ainda que ela agisse sempre, não se descobre sempre seus efeitos: o tempo os revela de época em época, e ainda que sempre igual em si mesma, ela não é sempre igualmente conhecida (...)" (PASCAL, 1963, p. 231b). Assim, se a Natureza revela seus segredos em diferentes épocas, embora sempre igual em si mesma, “(...) ela não é sempre igualmente conhecida (...)” (Idem, p. 231b), pois tudo o que dela se afirma com certeza hoje, poderá não ser tão certo amanhã. Não há verdades eternas como deseja Descartes. A certeza é sempre mesclada com a incerteza, a verdade com a falsidade. O que procura mostrar o filósofo é a distância que há entre nossas concepções e a "realidade das coisas". Se podemos estabelecer relações entre as coisas, e isso corretamente, pois “(...) o conhecimento de uma coisa liga-se ao conhecimento de outra (...)" (B.72; L.199), não podemos determinar o vínculo entre nossas concepções e a natureza (realidade das coisas), isto é, sua realidade. O mundo é o que nos aparece, e isto resulta do nosso ponto de vista.

Se não podemos determinar a realidade da natureza, disso segue que, “(...) por mais que ampliemos as nossas concepções (...)” concebemos “(...) tão-somente átomos em comparação com a realidade das coisas” (B.72; L.199). Nossas concepções são como que um ponto indivisível diante da realidade das coisas. Este ponto nada acrescenta: “(...) todo esse mundo visível é apenas um traço imperceptível na amplidão da natureza, que nem sequer nos é dado conhecer mesmo de um modo vago (...)" (B.72; L.199). Nossas concepções, portanto, não abarcam a natureza infinita. Procurar aplicar as ideias matemáticas à realidade é mero artifício, uma tentativa de apoderar-se 
da realidade, “(...) determinando-a pelos nossos conceitos e resumindo-a em nossas fórmulas” (COUTURAT, 1973, p. 535-536) ${ }^{10}$. A visão infinitista do universo, oriunda das matemáticas, não se vincula à realidade. A Geometria não sustenta o mundo físico.

Assim, se Pascal faz referência ao infinito atual nesta passagem do fragmento B.72; L.199: “(...) por mais que ampliemos as nossas concepções (...)”, tal como sustenta Cantor desse infinito atual (realidade das coisas) nada podemos conhecer, posto que nossas concepções (geométricas) não $\mathrm{O}$ abarcam. Diferentemente do infinito que encontramos no fragmento B.233; L.418: a possibilidade infinita de sempre acrescentar a unidade ao número sem jamais encontrar um termo que detenha esse processo, uma vez que unidade e número são homogêneos; no fragmento B.72; L.199, a natureza concebida matematicamente e a realidade são heterogêneas: “(...) as ideias matemáticas não representam as coisas reais”. Assim como as três ordens são autônomas por serem heterogêneas, do mesmo modo a realidade tem sua autonomia em relação à natureza concebida matematicamente; e, da mesma maneira que é impossível estabelecer uma passagem de uma ordem à outra, por haver uma "distância infinita" entre elas, não podemos medir a realidade com nossas concepções matemáticas. Não há passagem do possível ao real. E o que esgota a impossibilidade de conhecer o infinito atual é que se a Natureza é infinita, desse infinito da Natureza só conhecemos sua existência e não sua natureza. Sem esse conhecimento nenhuma passagem é possível do duplo infinito ao infinito atual.

Sempre é a partir do homem que o filósofo refere-se ao infinito. Sempre é o homem que ocupa o lugar central em suas especulações acerca do infinito. Todavia, é a própria concepção pascaliana de matemática que permite a ele situar o homem no centro de suas especulações: ciência de relações. As lições de geometria, duplo infinito presente na natureza, ensinam o lugar do homem: situado entre o nada e o infinito. Encontramos também as lições de geometria no fragmento B.233; L.418 dos Pensamentos. conhecemos a existência do infinito e não sua natureza, “(...) porque tem extensão como nós, mas não limite como nós”. É esta ignorância do infinito, porque não tem nenhuma proporção com o homem que vai dar, inclusive, o título do fragmento B.72; L.199: "desproporção do homem". Com efeito, se

$10 \mathrm{O}$ autor critica a tentativa daqueles que procuram, pela lógica das construções matemáticas, sustentar uma cosmologia racional: "as idéias matemáticas não representam as coisas reais". 
a Geometria ensina o lugar do homem, ela fornece a chave para que o homem compreenda a si mesmo. No fragmento B.72; L.199, o homem é levado a descobrir sua desproporção diante do infinito. No fragmento B.233; L.418 é levado a sentir sua finitude: "(...) o finito se aniquila na presença do infinito e torna-se um puro nada”.

Sempre é em relação a nós que o infinito é tomado. Isto implica que, não encontramos em Pascal um conceito positivo do infinito. Mesmo a ausência de limite do infinito, que afirma o filósofo, não é sacada da ideia do infinito, mas da relação com o homem. É por este viés que Pascal inverte o pensamento de Arquimedes (GARDIES, 1984, p. 83 e MONDOLFO, 1952, p. 543-544). Para Arquimedes "a potência do intelecto transcende infinitamente a realidade física”. Assim, Arquimedes resiste a passar da ideia à sua objetividade, pois a ideia ultrapassa a realidade. Pascal, embora considere Arquimedes o "príncipe dos geômetras", contrasta com seu pensamento. Segundo o filósofo, ao procurarmos captar a infinita realidade da natureza nossa imaginação antes se “(...) cansará de conceber do que a natureza de revelar” (B.72; L.199). Nenhuma ideia se aproxima da amplitude da realidade. O infinito não se deixa conceber. Nossas concepções ampliadas são como um átomo em comparação com a realidade das coisas. Assim, mesmo tendo Arquimedes como o príncipe dos geômetras, Pascal inverte seus pensamentos. O infinito nos é incompreensível.

Nesse conceito incompreensível é que Pascal faz desembocar a Geometria. Para conservar as propriedades do círculo por projeção nas diferentes secções cônicas, é necessário supor os “(...) encontros que se situam no infinito" (GARDIES, 1984, p. 102). E para encontrar a razão das diferentes secções cônicas, isto é, sua geração, é preciso escolher uma situação privilegiada que é o cume do cone de base circular: “(...) se o olho estiver situado no cume do cone, e se o quadro é o plano secante, então toda secção cônica, qualquer que ela seja, é a imagem da circunferência do círculo” (SERRES, 1968, p. 690). É então a situação do olhar que vai possibilitar encontrar a razão das diferentes secções cônicas. Isto que é impossível à razão conceber, ela é obrigada a admitir como, por exemplo, que a parábola “(...) se estende ao infinito e engendra um espaço infinito, embora ela seja a imagem da circunferência do círculo que é finita e que rodeia um espaço finito” (PASCAL, 1963, p. 40b).

Esse mesmo tema: o que à razão é impossível conceber, ela é obrigada a admitir, encontramos no fragmento B.233; L.418: a razão é 
obrigada a admitir a existência do número infinito, embora seja impossível a ela concebê-lo, uma vez que nossas definições, quando aplicadas a esse número, perdem todo seu sentido: do mesmo modo que as formas geométricas se dissolvem no infinito. Assim, se Pascal chega ao infinito atual dos números, ele não o adentra: o infinito atual nos é incompreensível.

É essa mesma incompreensibilidade do atualmente infinito que encontramos nos textos em que o filósofo trata do duplamente infinito. Tanto no opúsculo De l'esprit géométrique como no fragmento B.72; L.199 dos Pensamentos, o que falta ao homem é um lugar privilegiado do qual ele possa compreender a "realidade das coisas". Sempre situado distante dos extremos (princípio e fim) do universo, não há nenhuma possibilidade de o homem estabelecer no duplo infinito que caracteriza a natureza, um "corte objetivo" que o leve a compreender sua realidade. Sem um lugar privilegiado a experiência humana do duplo infinito da natureza é a possibilidade de sempre conceber um maior ou um menor sem encontrar limite a este poder. É precisamente isto que ensina a Geometria. Com efeito, deste poder do homem resulta que sua experiência da natureza só pode ser a do infinito potencial. E como conseqüência do universo tomado como duplamente infinito, a impossibilidade de um lugar privilegiado para conceber objetivamente a "realidade das coisas", ou seja, compreender o infinito interdita toda tentativa de encontrar o infinito atual.

A Geometria, porque Pascal a faz desembocar no infinito, nos conduz àquilo que ela não compreende. Utilizada como modelo para o verdadeiro conhe-cimento do universo, com ela, o mundo físico pascaliano não tem sustentação.

\section{Conclusão}

A geometria pascaliana que o faz trabalhar com o conceito de infinito apenas como operação, interdita à razão humana o conhecimento de tudo o que não está em relação com o humano. A razão não pode estabelecer relações entre coisas heterogêneas. Ora, o conceito de infinito atual (perfeição) é desproporcional ao humano, como então a razão poderá estabelecer relações entre ambos? Deus, por sua vez, por não ter partes nem limites não tem nenhuma relação conosco, não pode ser objeto da razão. Sem o conhecimento de Deus, como encontrar os fundamentos (origens) do 
mundo físico? Como compreendê-lo, uma vez que o que caracteriza a realidade das coisas é a dupla infinitude? A geometria, tal como Pascal a concebe, está em perfeito acordo com a teologia do Deus absconditus. Aquela foi desenvolvida considerando esta.

\section{Referências bibliográficas}

AgOstinho, S. A Cidade de Deus. Petrópolis: Vozes, 1990.

ARISTÓTELES. Physique. Paris: Les Belles Lettres, 1926.

ARNAULD, A.; NICOLE, P. La logique ou l'art de penser. Paris: Flammarion, 1970.

BELAVAL, Y. Leibniz critique de Descartes. Paris: Gallimard, 1960.

BLANCHOT, M. L'entretien infini. Paris: Gallimard, 1969.

BLAY, M. Les raisons de l'infini: du monde clos à l'univers mathématique. Paris: Gallimard, 1993.

BRAS G. ; CLÉRO, J. P. Pascal figures de l'imagination. Paris : PUF, 1994.

BURBAGE, F. CHOUCHAN, N. Leibniz et l'infini. Paris : PUF, 1993.

CHEVALLEY, C. Pascal contingence et probabilités. Paris : PUF, 1995.

COUTURAT, L. De l'infini mathématique. Paris: A. Blanchard, 1973.

DESCARTES, R. Discurso do método. São Paulo: Abril Cultural, 1973. (Os Pensadores).

Pensadores).

Meditações metafísicas. São Paulo: Abril Cultural, 1973. (Os

GARDIES, J. L. Pascal entre Eudoxe et Cantor. Paris: J. Vrin, 1984.

LEIBNIZ. G. Discurso de metafísica. São Paulo: Abril Cultural, 1983. (Os Pensadores).

. A monadologia. São Paulo: Abril Cultural, 1983. (Os Pensadores). . Novos ensaios sobre o entendimento humano. São Paulo: Abril

Cultural, 1980. (Os Pensadores).

MONDOLFO, R. El infinito en el pensamiento de la antigüidad clásica. Buenos Aires : Imán, 1952.

PASCAL. B. Oeuvres complètes. Organização por Louis Lafuma. Paris: Seuil, 1963. . Pensamentos. São Paulo: Nova Cultural, 1988. (Os Pensadores). . Pensamentos. São Paulo: Martins Fontes, 2001. 
RADICE, L. L. O infinito. De Pitágoras a Cantor. Itinerários filosóficos e matemáticos de um conceito de base. Lisboa, Notícias, 1981.

SERRES, M : Le système de Leibniz et ses modéles mathématiques. Paris: PUF, 1968.

Email: parraz@uol.com.br

Recebido: junho de 2010 Aprovado: dezembro de 2010 